\title{
La mineralogía en la estimación de las temperaturas de los incendios forestales y sus efectos inmediatos en Andosoles, Estado de México
}

\section{Mineralogy in the estimation of the temperature of forest fire and their immediate effects in Andosols, State of Mexico}

\begin{abstract}
Gabriel Alejandro Hernández Vallecillo', Ma. del Carmen Gutiérrez Castorenal*, Sandra Monserrat Barragán Maravilla', Efraín Reyes Ángeles Cervantes ${ }^{2}$, Edgar Vladimir Gutiérrez Castorena ${ }^{3}$ y Carlos Alberto Ortiz Solorio'
\end{abstract}

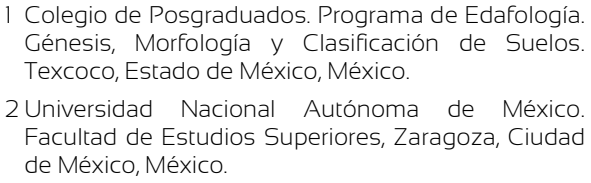

\author{
3 Universidad Autónoma de Nuevo León. Facultad de * Autor de correspondencia. castor@colpos.mx \\ Agronomía. Cd. Gral. Escobedo, Nuevo León, México.
}

\section{RESUMEN}

El fuego es un fenómeno natural e indispensable dentro de los ciclos biogeoquímicos de los suelos, sobre todo aquellos que sustentan una vegetación forestal como los Andosoles. No obstante, poco se conoce sobre las temperaturas que se alcanzan en el suelo y su efecto inmediato sobre sus propiedades edáficas. En 2017 se realizaron recorridos de campo en Texcoco, Estado de México, dos días después de que ocurrió un incendio forestal en Quercus sp y Pinus sp. Muestras de suelo compuestas e inalteradas se colectaron en los primeros 5 cm de suelo para el análisis de sus propiedades edáficas y micro-morfológicas. La estimación de la temperatura se realizó a través de un experimento térmico y análisis mineralógico. Con base en la destrucción, formación y dominancia principalmente de óxidos, ferromagnesianos y pseudoarenas, las temperaturas alcanzadas en los incendios forestales se agruparon en: < $250{ }^{\circ} \mathrm{C}$ en incendios superficiales y de copa de cualquier tipo de vegetación y $250{ }^{\circ} \mathrm{C}-500{ }^{\circ} \mathrm{C}$ cuando árboles caídos y raíces de árboles continuaron incinerándose. Materia orgánica, $\mathrm{pH}$, capacidad de intercambio catiónico, $\mathrm{P}, \mathrm{K}^{+} \mathrm{y} \mathrm{Na} \mathrm{Na}^{+}$y textura muestran tendencias directas e indirectas de acuerdo con el tipo de cenizas y temperatura y no con la severidad y tipo de vegetación. Los incendios superficiales y de copa modificaron de inmediato las propiedades de los Andosoles y mejoraron su calidad, mientras que, en aquellos puntos donde se alcanzaron temperaturas más altas, el suelo se vio afectado, pero esta perturbación se considera de menor impacto por presentarse en áreas reducidas.

PALABRAS CLAVE: cenizas, microestructura, mineralogía, pseudoarenas, severidad del fuego.

\section{ABSTRACT}

Fire is a natural phenomenon and indispensable within the biogeochemical cycles of soils, especially those that sustain a forest vegetation as in the case of Andosols. Nevertheless, little is known about the temperatures that are reached in the soils in forest fires, and their immediate effect on their edaphic properties. In April 2017, field trips were conducted in San Pablo Ixayoc, Texcoco, State of Mexico, two days after the start of the forest fire. Composite and unaltered soil samples in the first $5 \mathrm{~cm}$ of soil were collected for the analysis of their edaphic and micro-morphological properties. The estimation of the temperature was made through a thermal experiment and mineralogical analysis. Based on the destruction, formation and dominance mainly of the oxides, ferromagnesian and pseudo-sands, the temperatures reached in the forest fires can be grouped in: $<250{ }^{\circ} \mathrm{C}$ for superficial and crown fires in Quercus sp. and Pinus sp., and 250 ${ }^{\circ} \mathrm{C}-500{ }^{\circ} \mathrm{C}$ in fallen trees and tree roots that continued to be incinerated. The MO, pH, CIC, $\mathrm{P}, \mathrm{K}^{+}$and $\mathrm{Na}^{+}$and texture show direct and indirect tendencies according to the type of ashes and temperature and not with the severity and type of vegetation. Surface and crown fires immediately modified Andosols' properties and improved their quality, while, at those points where higher temperatures were reached, the soil is affected but there is less impact because fires occur in specific and small areas.

KEYWORDS: ash, micro-structure, mineralogy, pseudoarenas, fire severity. 


\section{INTRODUCCIÓN}

Los Andosoles son suelos formados a partir de cenizas volcánicas con propiedades físicas, químicas y mineralógicas muy particulares (Shoji y Takahashi, 2002), sobre todo cuando el material parental tiene un grado avanzado de alteración y las propiedades ándicas están bien expresadas (Nanzyo, 2002). Estos suelos se caracterizan por presentar materiales amorfos como ferrihidrita, alofano e imogolita, con densidades aparentes bajas y alta retención de fosfatos (Yamada y Shoji, 1983). Además, tienen un alto contenido de materia orgánica, la cual se acumula como hojarasca y formar un horizonte "O" o bien humificarse y originar un horizonte " $\mathrm{A}$ " de gran espesor ya sea con vegetación forestal o de pastizales (Boul, Southard, Graham y McDaniel, 2011). La alta actividad biológica de estos suelos forma agregados migajosos y granulares que permiten alta retención de humedad y percolación de agua y (Stoops, 2007). Un rasgo frecuente es la presencia de residuos carbonizados que se pueden encontrar no solo en la superficie del suelo, sino también en los diferentes horizontes o capas de los Andosoles, lo que significa que han coevolucionado con los incendios forestales. En ese sentido el fuego debe ser indispensable para sus ciclos biogeoquímicos al mejorar la calidad del suelo, o bien los suelos tienen alta resiliencia debido a sus propiedades físicas como alto contenido de humedad y propiedades térmicas tan particulares (Brady y Weil, 1999). Los estudios que se han llevado a cabo sobre los incendios forestales indican que modifican las propiedades del suelo, sobre todo en los primeros centímetros de profundidad (Neary, Ryan y DeBano, 2005), haciéndolos más rojizos (Bodi et al., 2014), e incrementando su contenido de materia orgánica por la incorporación de cenizas (Certini, 2005) y su pH (Heydary, Rostamy y Dey, 2017).

Las temperaturas que se pueden presentar directamente en el suelo han sido documentadas principalmente a través de incendios prescritos (MataixSolera y Guerrero 2007). Certini (2005) encontró que a 100 ${ }^{\circ} \mathrm{C}$ el agua contenida en el suelo se evapora rápidamente; aunque esta propiedad se puede restablecer inmediatamente después de una lluvia y modificar nuevamente las fuerzas de adhesión-cohesión (Brady y Weil, 1999). Sin embargo, poco se ha documentado sobre los cambios en la mineralogía de Andosoles después de un incendio.

A través de análisis térmicos diferenciales se ha encontrado que el vidrio volcánico se destruye a $150{ }^{\circ} \mathrm{C}$ (Drees, Wilding, Smeck y Senkari, 1989), la ferrihidrita > $300{ }^{\circ} \mathrm{C}\left(\mathrm{Fe}_{2} \mathrm{O}_{3} \bullet 0.5\left(\mathrm{H}_{2} \mathrm{O}\right)\right.$ se trasforma a hematita $\mathrm{Fe}_{2} \mathrm{O}_{3}$ (Taylor, 1990), las esmectitas pierden su agua a $>300{ }^{\circ} \mathrm{C}$ (Borchardt, 1989) y los feldespatos se destruyen $>1000{ }^{\circ} \mathrm{C}$ (Avgustinik, 1983). De acuerdo con Mataix-Solera y Guerrero (2007) estas temperaturas se pueden alcanzar cuando se incendian los pastizales $\left(177^{\circ} \mathrm{C}-700{ }^{\circ} \mathrm{C}\right)$, los pinares $\left(135^{\circ} \mathrm{C}-1150^{\circ} \mathrm{C}\right)$ y los bosques densos (hasta 700 ${ }^{\circ} \mathrm{C}$ ), por lo que se deben de presentar cambios en la mineralogía del suelo superficial.

Por otra parte, cuando ocurre un incendio se evalúa el daño que causa a la vegetación y de manera cualitativa se clasifica su severidad a través de la presencia de materia orgánica arriba o abajo del suelo y grado de combustión. La severidad de los incendios se clasifica como baja, moderada y alta (Simard, 1991), o bien como subterráneos, superficiales y de copa o corona de acuerdo con la Comisión Nacional Forestal [Conafor] (2010). En el caso del suelo, no hay una clasificación del daño que puede ocasionar un incendio de acuerdo con la temperatura, debido a que los cambios no son evidentes, sobre todo en las propiedades químicas y mineralógicas. Esta ausencia de conocimiento de los procesos que ocurren en el suelo después de un incendio no permite comprender el porqué de su comportamiento dual en los ecosistemas (Shvidenko y Nilsson, 2000); es decir, pueden resultar benéficos incrementando la calidad del suelo o perjudiciales y limitar su posterior regeneración o reforestación. Además, los estudios se realizan años después de ocurrido el fenómeno, donde la lluvia y los procesos erosivos ya han actuado. Con base en el análisis teórico las hipótesis que se plantean son: la temperatura alcanzada en un incendio forestal se puede estimar a través de la mineralogía de los Andosoles y los 
cambios en las propiedades del suelo están relacionadas con la severidad del fuego y el tipo de vegetación.

\section{OBJETIVOS}

Los objetivos de la presente investigación fueron: 1) Determinar la temperatura alcanzada a través de su mineralogía en condiciones controladas y naturales; y 2) Evaluar el efecto inmediato e in situ de los incendios forestales superficiales y de copa en las propiedades edáficas de Andosoles en dos tipos de vegetación.

\section{MATERIALES Y MÉTODOS}

\section{Área de estudio}

La zona de estudio se ubica en la comunidad de San Pablo Ixayoc, en el municipio de Texcoco, Estado de México (Fig.
1). El área de estudio se localiza a los $19^{\circ} 26^{\prime} 42^{\prime \prime}$ de latitud norte y $98^{\circ} 46^{\prime} 45^{\prime \prime}$ de longitud oeste, a una elevación de $2970 \mathrm{~m}$ snm. El clima es templado subhúmedo con lluvias en verano $\left(\mathrm{Cw}_{2}\right)$, con una temperatura media anual de 15 ${ }^{\circ} \mathrm{C}$ (García, 1998). La vegetación corresponde a bosques naturales de encinos (Quercus rugosa y Q. laurina.) y plantaciones forestales de pino (Pinus teocote, Pinus montezumae, Pinus patula y Pinus radiata), con vegetación secundaria de pastos y algunos individuos de otras especies arbóreas, como Cupressus lusitanica, Arbutus xalapensisy Alnus firmifolia. El material parental del suelo corresponde a cenizas volcánicas de naturaleza intermedia según la clasificación de Heinrich (1972). El suelo se clasificó como un Umbric Andosols (Siltic) (The International Union of Soil Science [IUSS], Grupo de Trabajo de la World Reference Base [WRB] (2015).

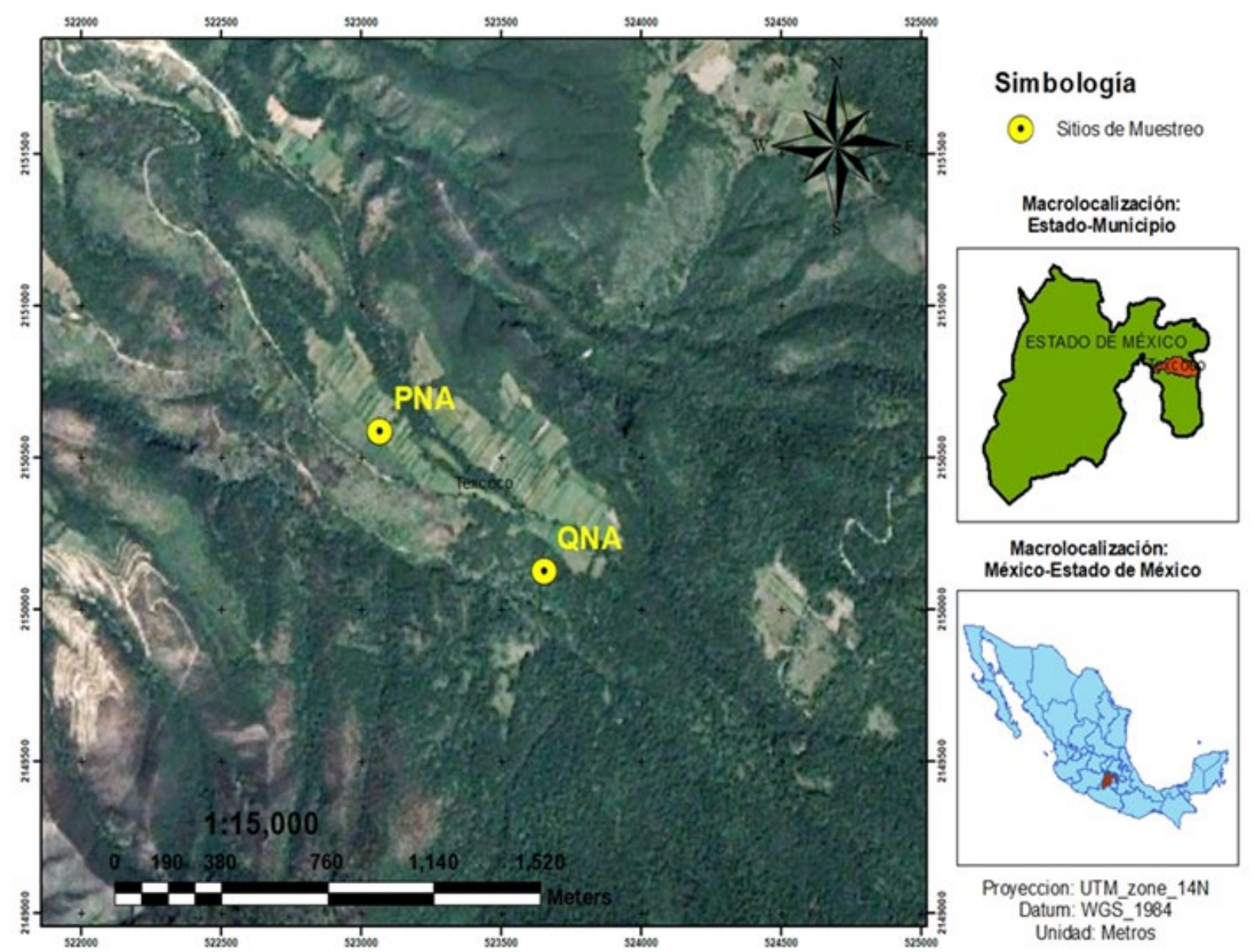

FIGURA 1. Localización del sitio de estudio. 


\section{Trabajo de campo}

El área de estudio resultó afectada por un incendio forestal que ocurrió durante cinco días, entre el 2 y 6 de abril de 2017. Durante el tercer día se efectuaron recorridos de campo en donde los comuneros permitieron el acceso y se seleccionaron los sitios de muestreo. En el cuarto y quinto día se realizó la colecta de muestras y en la noche de este último día se presentaron precipitaciones lo cual transformó las condiciones inmediatas e in situ generadas por el incendio y limitó continuar con el muestreo.

Con base en la propuesta de la Conafor (2010) se seleccionaron un total de 12 sitios con diferente intensidad y tipo de vegetación. En bosque de Quercus se ubicaron 6 sitios: no afectado (QNA), afectados por incendios superficiales (QIS) e incendios de copa (QIC), así como zonas partículas en donde los árboles se consumieron en su totalidad: árbol base $(\mathrm{AB})$, árbol caídos (AC) y zona adyacente (AA), donde el color de cenizas era más claro que el resto de la zona. En cada sitio se registraron características morfológicas de la hojarasca y de las cenizas (color y espesor) y se excavó el horizonte superficial del suelo $(0 \mathrm{~cm}-10 \mathrm{~cm}$ de profundidad $)$ para evaluar el cambio de color.

En las plantaciones de Pinus sp. (Pinus teocote, Pinus montezumae., Pinus patula y Pinus radiata), se seleccionaron 6 sitios: no afectado (PNA), afectados por incendios superficiales (PIS) e incendios de copa (PIC) y dentro de los incendios de copa se seleccionaron sitios con asociaciones pino-pastizal, pino Cupressus lusitanica y pino Arbutus xalapensis Además, se analizó un hueco de árbol $(30 \mathrm{~cm}$ de diámetro por $80 \mathrm{~cm}$ de profundidad), que quedó después de que se consumió totalmente la raíz principal y donde se registró una temperatura $>200^{\circ} \mathrm{C}$. Por su morfología, estos huecos se denominaron "Hornos".

En cada sitio seleccionado se colectaron de manera aleatoria cinco muestras compuestas de suelos alterados y muestras inalteradas utilizando cajas tipo Kubiena de los primeros cinco centímetros de profundidad. En el "Horno" se obtuvieron cuatro muestras de la cara adyacente a lo que fue la raíz a diferentes profundidades $0 \mathrm{~cm}-5 \mathrm{~cm}, 10 \mathrm{~cm}$ $30 \mathrm{~cm}, 30 \mathrm{~cm}-60 \mathrm{~cm}$ y $>60 \mathrm{~cm}$, con base en su color y consistencia. Cada muestra se guardó en bolsas de polietileno y se etiquetaron para su posterior análisis en laboratorio y elaboración de secciones delgadas.

\section{Trabajo de laboratorio}

\section{Estimación de la temperatura alcanzada en los suelos.}

Esta parte del estudio comprende dos etapas: experimento térmico y análisis mineralógico de muestras de suelos afectados y no afectados por incendios forestales.

Experimento térmico. Consistió en pesar $50 \mathrm{~g}$ de suelo de los bosques no afectados (sin tamizar y con restos de material vegetal) y se colocaron en crisoles; posteriormente, las muestras fueron sometidas a tres temperaturas: $250{ }^{\circ} \mathrm{C}$, $500{ }^{\circ} \mathrm{C}$ y $750{ }^{\circ} \mathrm{C}$ utilizando una mufla (Scorpion Scientific). Giovannini y Lucchesi (1997) recomiendan que primero se alcance la temperatura deseada en la mufla y luego se coloquen las muestras de suelo al choque térmico durante 30 min.

Análisis mineralógico. Tanto la fracción arenosa como la arcillosa se obtuvieron mediante el análisis de textura con el método de la pipeta americana. Las arenas gruesas $(500 \mu \mathrm{m}$ - $1000 \mu \mathrm{m}$ ) se separaron con un tamiz y se montaron en un portaobjeto. Los minerales se identificaron a través de sus propiedades ópticas (transparentes, opacos y de color) utilizando un microscopio petrográfico con cuatro fuentes de luz: polarizada plana (LPP), polarizada cruzada (LPC), incidente (LI) y fluorescencia (FL). Los granos minerales se contabilizaron cuadrante por cuadrante $\left(0.5 \mathrm{~mm}^{2}\right)$ hasta alcanzar 100 granos y se obtuvieron sus porcentajes. La fracción arcillosa se obtuvo de la arcilla en suspensión, para ello se extrajo un alícuota $(1 \mathrm{ml})$ y se depositó en un portaobjetos para que se orientaran. Estas metodologías fueron extraídas del Manual de Van Reeuwijk (2002). Las arcillas orientadas fueron colocadas en el equipo de rayos $\mathrm{X}$ (marca GBC 122D) empleando la técnica de barrido a una velocidad de $4^{\circ} \mathrm{min}^{-1}$, desde $2^{\circ}$ hasta $60^{\circ}$ y los minerales se identificaron a través de sus ocho principales reflexiones utilizando la base de datos del International Centre for Diffration Data [ICDD] (2002). Finalmente, a través de estadísticas descriptivas se comparó la mineralogía de cada 
fracción de todas las muestras analizadas y se estimó la temperatura alcanzada durante el incendio forestal con base en la formación, destrucción y abundancia de los minerales.

Análisis de las propiedades edáficas. Las muestras de suelo se dejaron secar a la sombra a temperatura ambiente; posteriormente, se maceraron y tamizaron para obtener la fracción de tierra fina del suelo $(<2 \mathrm{~mm})$. Las propiedades analizadas fueron: $\mathrm{pH}$ (1:2.5, suelo: agua); porcentaje de carbono orgánico (CO) y materia orgánica (MO) (WalkleyBlack), capacidad de intercambio catiónico (CIC) y bases intercambiables $\mathrm{Ca}^{++}, \mathrm{Mg}^{++}, \mathrm{K}^{+}, \mathrm{Na}^{+}$(acetato de amonio). Además, se determinó el nitrógeno total Nt (microKjeldalhl), fósforo soluble P (Olsen), carbonatos totales $\mathrm{CaCO}_{3}$ (titulación rápida de Piper), color (carta de colores Munsell), textura (pipeta americana), retención de humedad RH (olla de presión) y densidad aparente Dap (probeta). Todas las metodologías fueron extraídas del manual de procedimientos de Van Reeuwijk (2002).

Análisis micromorfológico. Las muestras inalteradas secas se impregnaron con resina poliéster insaturada y monómero de estireno (proporción 7:3) y posteriormente se elaboraron secciones delgadas $(7 \times 5.5 \times 30) \mu \mathrm{m}$, utilizando la metodología de Murphy (1986). Los componentes básicos del suelo que se describieron fueron: estructura, porosidad, minerales y materia orgánica con base en los conceptos y terminología de Stoops (2003). Además, las cenizas se analizaron en luz polarizada cruzada (LPC) para determinar su naturaleza cálcica y con Luz Fluorescente (UV) para establecer si son fosfatadas (Karkanas y Goldberg, 2018).

\section{Resultados}

\section{Tipos de incendio}

En la zona de estudio se encontró que el incendio forestal afectó a una vegetación natural de Quercus sp y plantaciones de Pinus sp. los cuales se mencionan en la figura 2. La vegetación de Quercus sp. (Q) no afectada (QNA) es un bosque natural (Fig. 2a), en donde la hojarasca tiene un espesor de cinco centímetros, con moderada o ligera descomposición y su arreglo laminar y compacta. En el incendio superficial, la hojarasca se quemó parcialmente dejando residuos carbonizados y cenizas negras de un espesor de tres centímetros.

La vegetación de Pinus sp. (P) no afectada (PNA) corresponde a una plantación forestal de los años setenta (Adame, Oropeza, Martínez, Santoyo y Ramírez, 2000) y también hay una fracción que está asociada con pastizales (Fig. 2g). Además, en la superficie del suelo se presenta una gran cantidad de acículas, bien preservadas y pasto seco, con un espesor de tres centímetros. El incendio superficial (PIS) quemó parcialmente la hojarasca dejando residuos carbonizados y cenizas negras de dos centímetros de espesor (Fig. 2h); mientras en el incendio de copa (PIC) se depositó una capa de cenizas y residuos orgánicos pirocalcinados únicamente debajo del dosel (Fig. 2i), con cenizas blancas, negras y grisáceas, de un espesor entre 2 $\mathrm{cm}$ a $3 \mathrm{~cm}$.

La vegetación de bosque de Quercus sp. y Pinus sp. afectada por el incendio superficial alcanzó a quemar a los árboles hasta $1.5 \mathrm{~m}$ de altura (Fig. 2b y h); mientras que en el incendio de copa (Fig. 2c, i y j) se consumió totalmente el follaje de los árboles y se depositaron en el suelo residuos carbonizados y cenizas. Además, en Quercus sp., el incendio quemó los árboles hasta reducirlos a cenizas, dejando únicamente la base del tronco (AB) (Fig. 2d) o bien los árboles cayeron consumiéndose en el suelo y dejaron su huella de cenizas (AC) (Fig. 2e). En Pinus sp. en donde las raíces continuaron consumiéndose y se formaron huecos u "Hornos" $(\mathrm{H})$, se presentó policromía en sus paredes desde amarillos hasta rojizos (Fig. 2k y l). En otros sitios, los pinos asociados con pastizales al quemarse dejaron cenizas blancas y grises (PPIC; Fig. 2j); mientras que en otras especies como Arbutus xalapensis (AXIC) y Cupressus lusitanica (CUIC) perdieron totalmente su follaje y quedó alrededor del árbol material calcinado y cenizas negras (10YR2/2) de un espesor de $3 \mathrm{~cm}$ y $5 \mathrm{~cm}$ respectivamente. Finalmente, tanto en bosque de Quercus como en plantación de Pinus el efecto de los incendios fue mayor en pendientes altas de las laderas. 


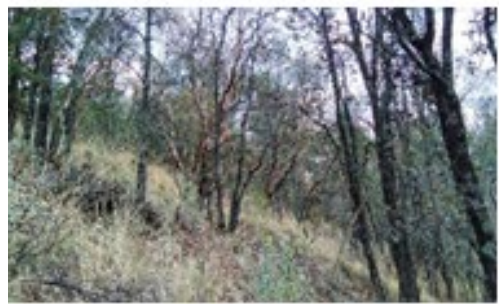

a. No afectado

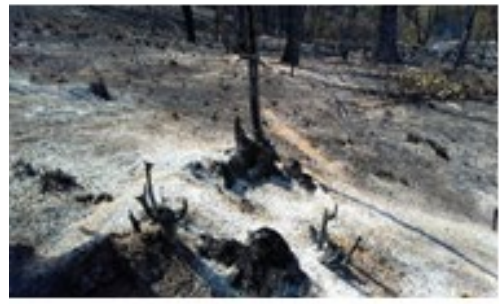

d. Tronco base incinerada

Vegetación de Quercus sp.

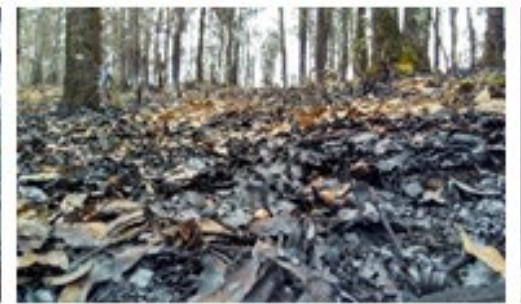

b. Incendio superficial

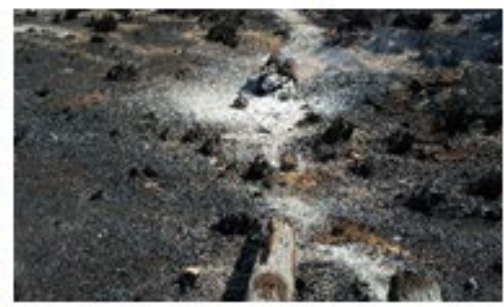

e. Árbol caído e incinerado

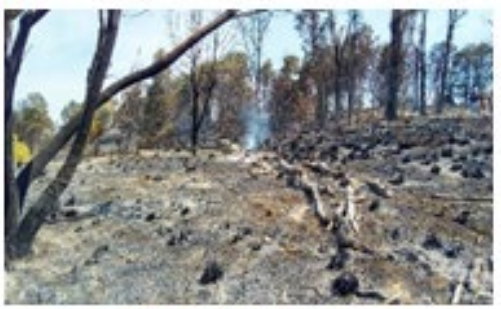

c. Incendio de copa

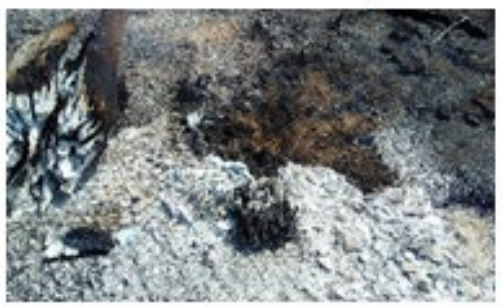

f. A un lado

Vegetación de Pinus sp.

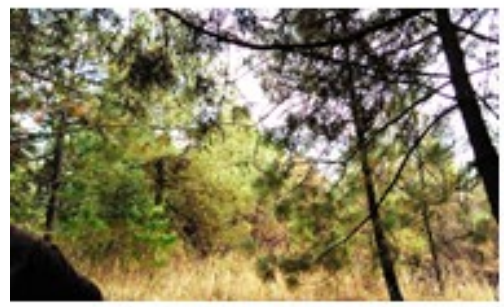

g. No afectado

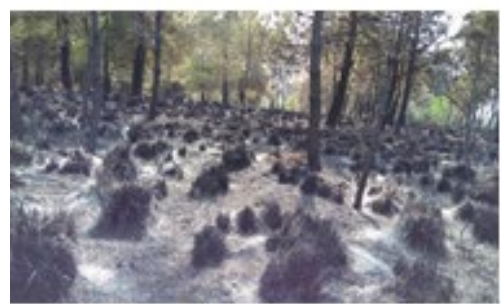

j. Incendio de copa pinopastizal

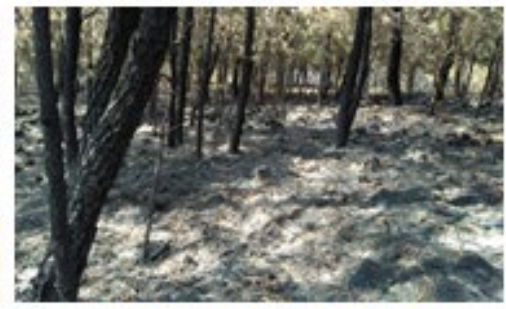

h. Incendio superficial

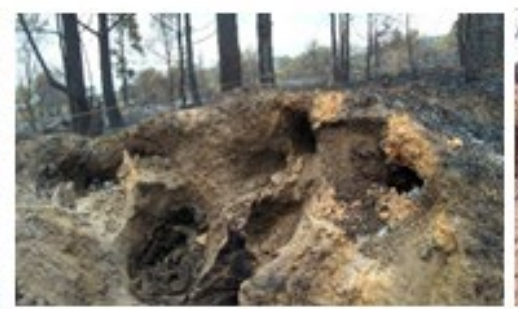

k. Incendio de copa

"Horno"

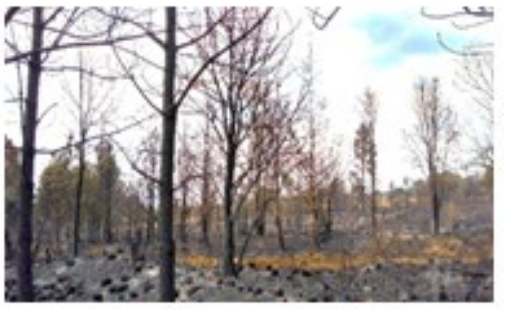

i. Incendio de copa

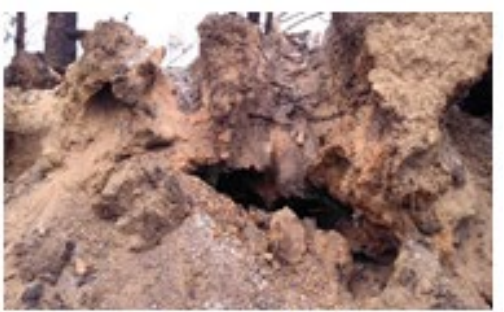

l. Incendio de

Copa "Horno"

FIGURA 2. Sitios afectados y no afectado por incendios forestales bajo diferentes tipos de vegetación.

Estimación de la temperatura de los incendios forestales a través de la mineralogía

La fracción gruesa de los sitios estudiados está compuesta por vidrio volcánico, feldespatos, ferromagnesianos (hiperstena, hornablenda, biotita y olivina) y cuarzo (Fig. 3a). Los minerales se fueron fragmentando con el incremento de la temperatura (Fig. 3b), se opacaron (Fig. 3c) y se tornaron rojizos (Fig. 3d) formado pseudoarenas. Los minerales que ocurren en los incendios superficiales y de copa no presentan minerales opacos, ni fragmentación como ocurre en las muestras de suelo no afectado; mientras que las arenas de los hornos se parecen en las características que presentan las arenas sometidas a temperaturas $>500$ ${ }^{\circ} \mathrm{C}$ (Fig. 3d). 

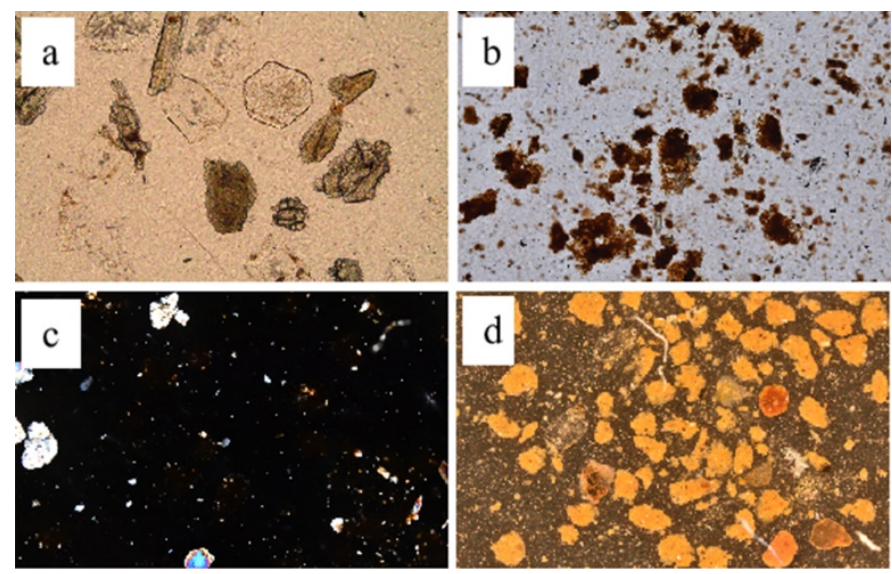

FIGURA 3. A) Fracción arenosa en sitio no afectado por incendios en LPC; b) fragmentos de arenas en choque térmico a $750{ }^{\circ} \mathrm{C}$, en LPP; c) los minerales y las pseudoarenas son opacos y no reflejan la luz en LPC); d) los mismos minerales y pseudoarenas ahora reflejan colores rojizos en luz incidente. c) y d) corresponden a arenas del horno de un incendio de copa en pino. Longitud del marco $2.9 \mathrm{~mm}$.

En la figura 4 se puede apreciar cómo los minerales aumentan o disminuyen sus porcentajes de manera regular de acuerdo con el incremento de la temperatura; es decir, mientras los vidrios volcánicos, feldespatos y cuarzo disminuyen, las pseudoarenas se incrementan considerablemente, desde 0 en suelo no afectado hasta $88 \%$ a temperaturas de $750{ }^{\circ} \mathrm{C}$. Con base en el comportamiento del vidrio volcánico y opacos se puede indicar que los incendios superficiales como de copa de ambos tipos de vegetación no sobrepasaron los $250{ }^{\circ} \mathrm{C}$. En condiciones específicas, las temperaturas oscilaron entre $250{ }^{\circ} \mathrm{C}$ y 500 ${ }^{\circ} \mathrm{C}$ en los encinos que continuaron incinerándose hasta su destrucción y en las capas superficiales de los hornos (H1 y $\mathrm{H} 2$ ); mientras que en las capas más profundas de los hornos ( $\mathrm{H} 3$ y H4), se estima que las temperaturas alcanzadas fueron más altas $\left(500{ }^{\circ} \mathrm{C}\right.$ y $\left.750{ }^{\circ} \mathrm{C}\right)$.

La fracción fina está integrada por minerales primarios como: cristobalita y cuarzo, feldespatos, ferromagnesianos (biotita, augita e hiperstena) y minerales secundarios como halloysita y óxidos de $\mathrm{Fe}$ como ferrihidrita. Con el experimento térmico se encontró que halloysita y ferrihidrita solo ocurren a $<250{ }^{\circ} \mathrm{C}$; augita e hiperstena y hematita solamente dominan entre $250{ }^{\circ} \mathrm{C}$ y $500{ }^{\circ} \mathrm{C}$ y los feldespatos y cuarzo son abundantes $>500{ }^{\circ} \mathrm{C}$. Con base en la destrucción, formación de hematita y dominancia de los minerales, principalmente de los óxidos de $\mathrm{Fe} y$ ferromagnesianos, las temperaturas alcanzadas en los incendios forestales se pueden agrupar en dos. Grupo 1 (< $250^{\circ} \mathrm{C}$ ), integrado por incendios superficiales y de copa de cualquier tipo de vegetación y Grupo $2\left(>250^{\circ} \mathrm{C}\right)$ en donde la incineración continuó ya sea en árboles caídos como en hornos.

\section{Propiedades edáficas}

Los cambios y tendencias en las propiedades químicas y físicas de ambos tipos de vegetación también están relacionados con la temperatura como se puede observar en la figura 5. En el Grupo 1, el pH se alcaliniza ligeramente (de 6.1 a 7.2), aumentan los contenidos de MO (de 11.5\% hasta $12.9 \%$ en $Q$ y de $5.3 \%$ hasta $7.91 \%$ en $P$ ) y los fosfatos disponibles (por ejemplo, en QIC fue de $39.0 \%$ a $72.6 \%$ ); mientras que disminuyen la CIC (hasta $6.6 \mathrm{cmoles} \mathrm{kg}^{-1}$ en

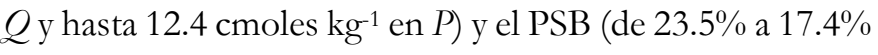
en $P$ ). Los colores son pardos oscuros y la clase textural se conserva en franco limosa; aunque el porcentaje de limos incrementa hasta $25 \%$ y la arena disminuye $19 \%$. 
Quercus sp.
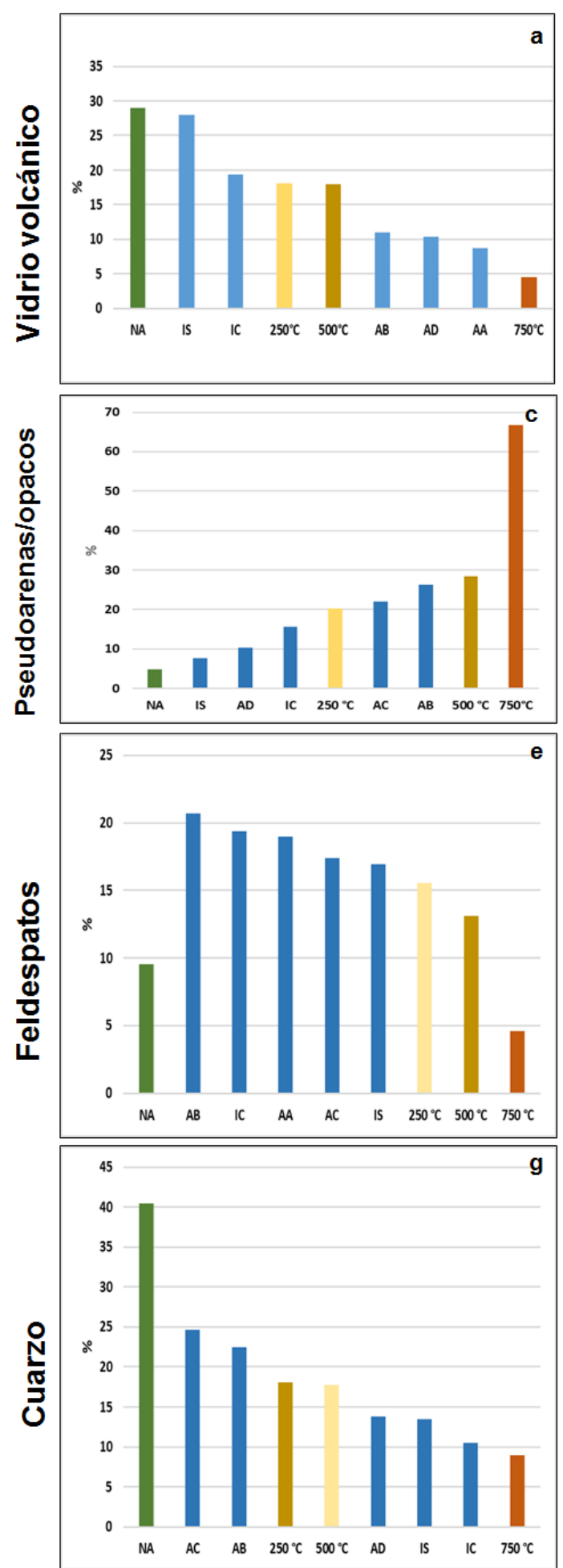

Pinus sp.
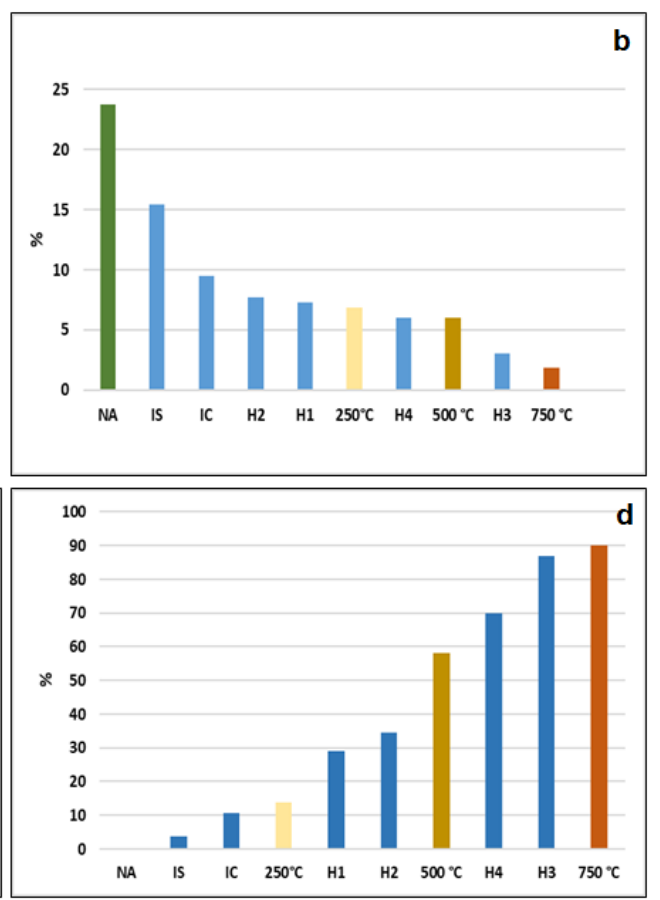

(20
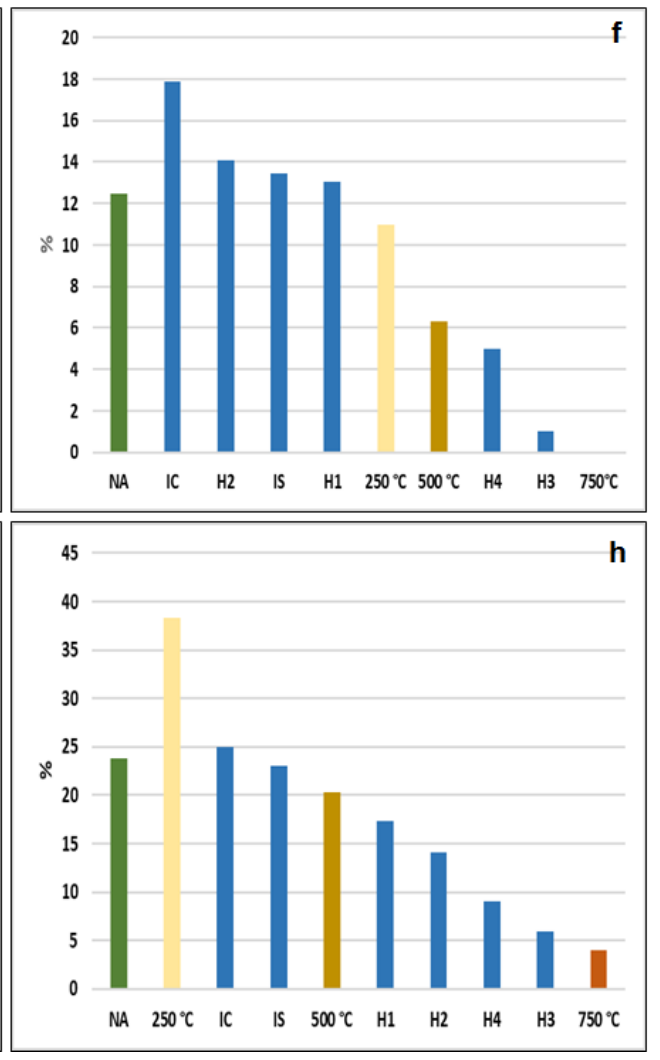

FIgURA 4. Mineralogía de la fracción gruesa de muestras de campo y de tratamiento térmico en bosque de Quercus sp; $\mathrm{NA}=$ no afectado; $\mathrm{I}=$ incendios; $\mathrm{S}=$ superficial; $\mathrm{C}=$ copa; $\mathrm{AC}=$ árbol caído; $\mathrm{AA}=$ árbol adyacente; $\mathrm{AB}=$ árbol base; $\mathrm{H} 1=0 \mathrm{~cm}$ a $10 \mathrm{~cm} ; \mathrm{H} 2=10 \mathrm{~cm}$ a $20 \mathrm{~cm} ; \mathrm{H} 3=20 \mathrm{~cm}$ a $40 \mathrm{~cm}$ y H4 = de 40 $\mathrm{cm}$ a $50 \mathrm{~cm}$. 


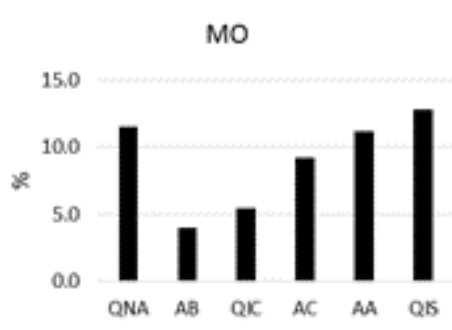

$\mathrm{Na}+$

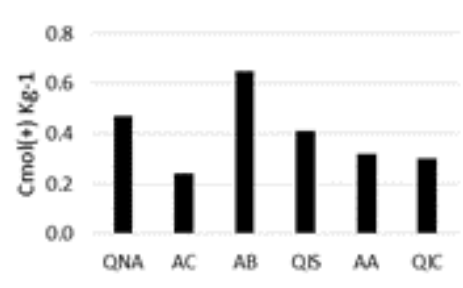

P2OS

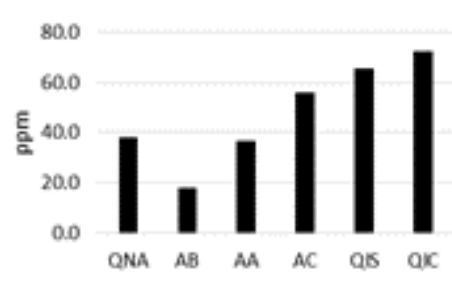

\% Arenas

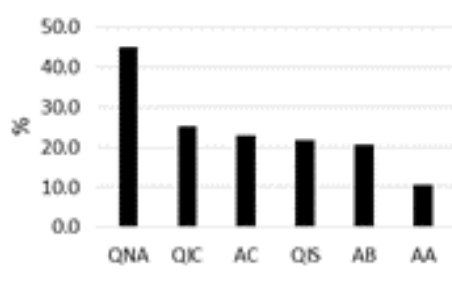

$\mathrm{CIC}$

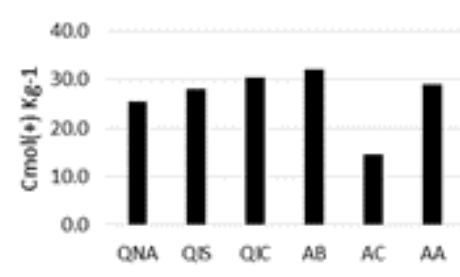

K+

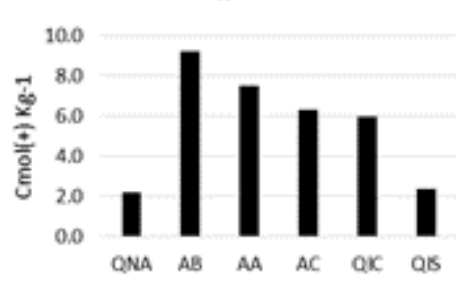

Capacidad de campo

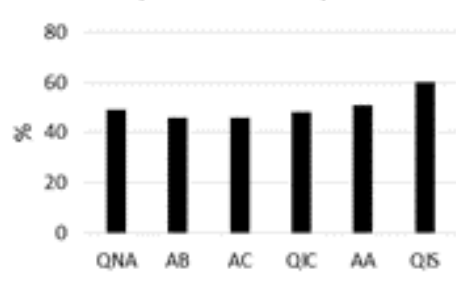

\% Limos

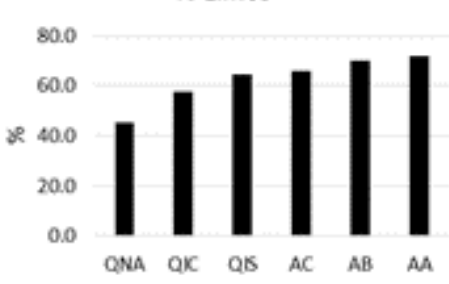

MO

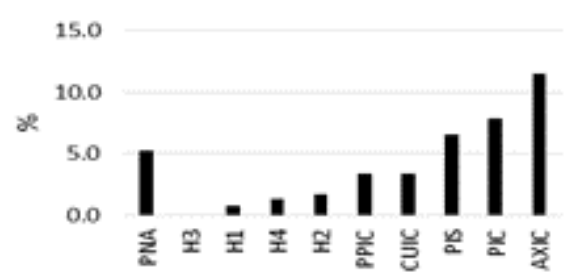

$\mathrm{Na}+$

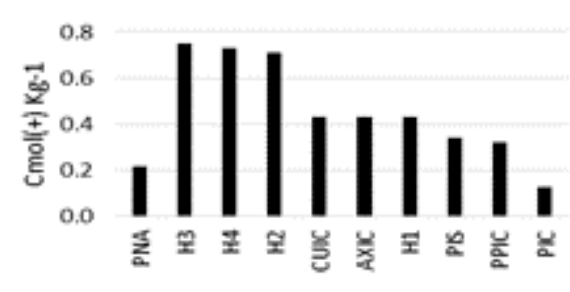

P2O5

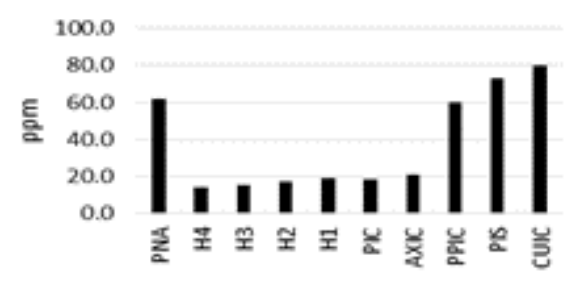

$\%$ Arenas

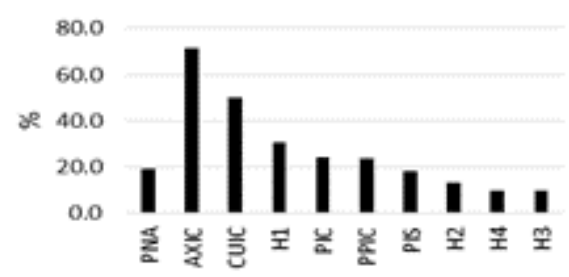

CIC

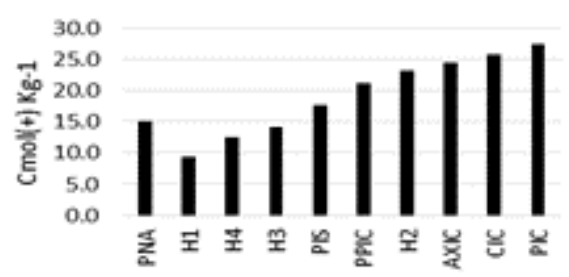

K+

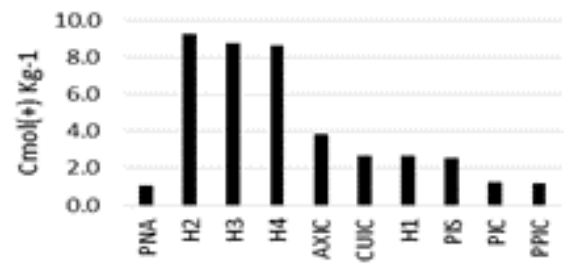

Capacidad de campo

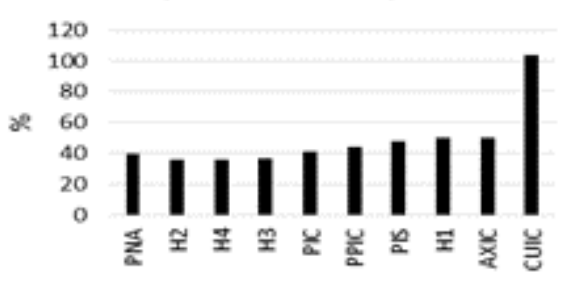

\% Limos

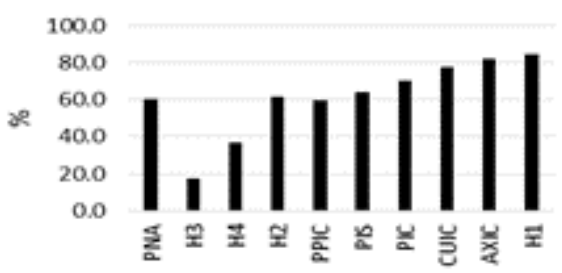

FIGURA 5. Propiedades físicas y químicas del suelo en dos tipos de vegetación; $\mathrm{Q}=$ Quercus sp. $\mathrm{P}=$ Pinus sp; $\mathrm{NA}=$ no afectado; $\mathrm{I}=$ incendios; $\mathrm{S}=$ superficial; $\mathrm{C}=$ copa; $\mathrm{AC}=$ árbol caído; $\mathrm{AA}=$ árbol adyacente; $\mathrm{AB}=$ árbol base; $\mathrm{H} 1=$ Horno $0 \mathrm{~cm}-5 \mathrm{~cm} ; \mathrm{H} 2=\mathrm{Horno} 10 \mathrm{~cm}-30 \mathrm{~cm} ; \mathrm{H} 3=\mathrm{Horno} 30 \mathrm{~cm}-60 \mathrm{~cm} ; \mathrm{H} 4=\mathrm{Horno}>60 \mathrm{~cm}$; AXIC = Arbutus xalapensis copa; PPIC $=$ Pinus-pastizal copa; CUIC $=$ Cupressus copa. 
En el Grupo 2, el pH se alcaliniza más el suelo (hasta 8.4 en $Q$ y 7.8 en $P$ ) y disminuyen los contenidos de $\mathrm{MO}$ (de $11.5 \%$ a $3.9 \%$ en $Q$ y de $5.27 \%$ hasta $0 \%$ en $P$ ) y el fosfato disponible (de $61.6 \%$ a $14.3 \%$ en Horno 4). En tanto que aumenta la CIC (hasta 7 cmoles $\mathrm{kg}^{-1}$ en $Q$ y hasta $12 \mathrm{cmol} \mathrm{kg}^{-1}$ en $P$ ) y los cationes intercambiables como $\mathrm{Na}^{+}$ y $\mathrm{K}^{+}$(dos y hasta siete veces más, en $Q$ y $P$, respectivamente). Los colores se hacen más amarillos (7.5 YR) incluso rojizos (2.5 YR 5/4), e incrementa la fracción arenosa (de $19.1 \%$ a $71.7 \%$ ) en detrimento de la fracción limosa y arcillosa. El contenido de humedad a capacidad de campo se reduce ligeramente $(<4 \%)$.

\section{Micromorfología}

En los sitios sin afectación de ambos tipos de vegetación predominan los residuos orgánicos de ligera a buena preservación, macro agregados migajosos granulares y poros de empaquetamiento compuesto (Fig. 6a). En los incendios superficiales los residuos se quemaron parcialmente (Fig. 6b), o se carbonizaron totalmente (Fig. 6c). En algunos casos el incendio no solo afectó a la hojarasca, sino también quemó agregados del suelo (Fig. 6d), incluso carbonizó las raíces sin afectar la matriz del suelo como ocurrió en incendios de copa (Fig. 6e). En las muestras del "Horno" hay un colapso de la estructura, la cual cambia a masiva reduciendo de manera drástica del porcentaje de poros de $30 \%$ en condición natural a 5\% y sin presencia de componentes orgánicos en su interior (Fig. 6f).

Componentes orgánicos y cenizas. Todas las muestras afectadas por incendios forestales presentaron deposición de material vegetal con distintos tamaños y grados de calcinación. Cuando la combustión es incompleta (Grupo 1), se depositaron residuos vegetales carbonizados en la superficie, en los que aún se diferencian órganos y tejidos vegetales (Fig. 7a y b). En el Grupo 2, como la incineración fue completa, se depositaron partículas muy finas en la superficie del suelo, con cenizas pardo-grisáceas (Fig. 7c), de naturaleza calcárea por su fábrica birrefringente cristalítica, como sucedió en Quercus (Fig. 7d), o bien con autoflorescencia como en Pinus (Fig. 7f).

\section{DISCUSIÓN}

\section{Mineralogía y temperatura del incendio forestal}

Los minerales se fragmentan por termoclasismo (dilatación y contracción) ya sea por su clivaje paralelo a las cadenas de la sílice que tienen los ferrogmagnesianos (Huang, 1989) o por la presencia de agua estructural que tienen los vidrios volcánicos que se evapora a $<150{ }^{\circ} \mathrm{C}$ (Drees et al., 1989). Además, estos minerales contienen $\mathrm{Fe}$ que al oxidarse opacan a otros minerales (Brownlow, 1996). Estos procesos están relacionados con las temperaturas de ahí que se incrementen los fragmentos y los opacos o pseudoarenas hasta ser dominantes a $750^{\circ} \mathrm{C}$.

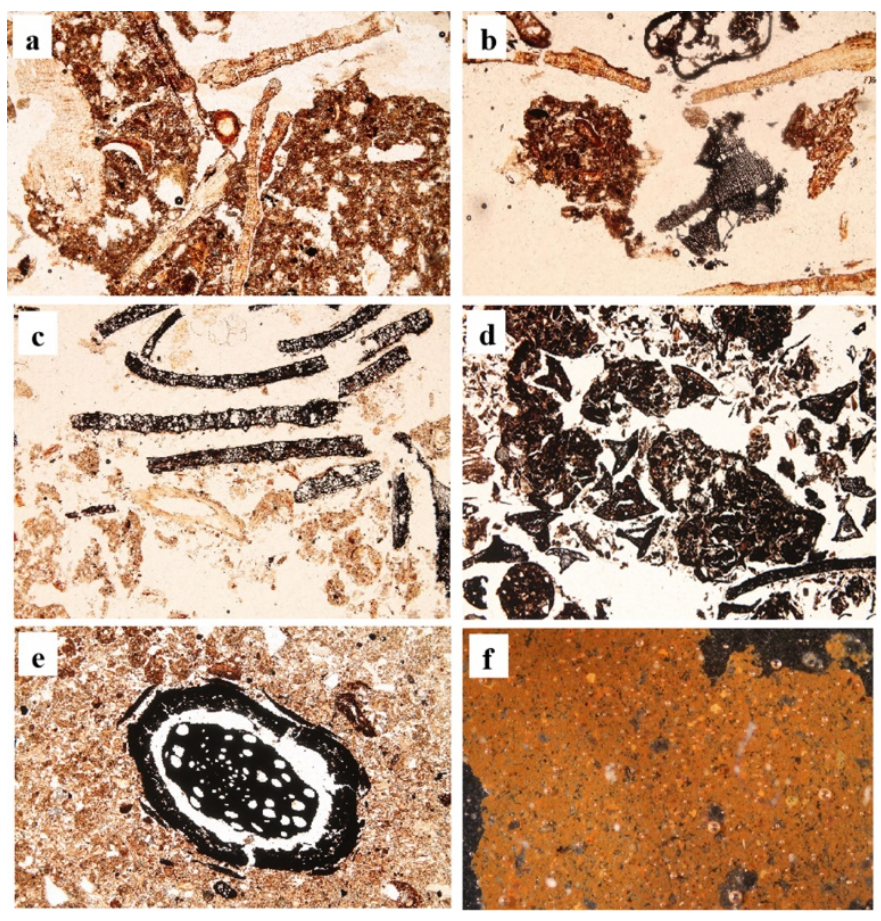

FigurA 6. Depósitos de acículas (A) parcial (B) o totalmente carbonizadas (C). Agregados quemados (D), raíces carbonizadas con una masa basal sin quemar (E) y estructura masiva (F) (B). Luz polarizada plana con una longitud del marco $5.3 \mathrm{~mm}$. 


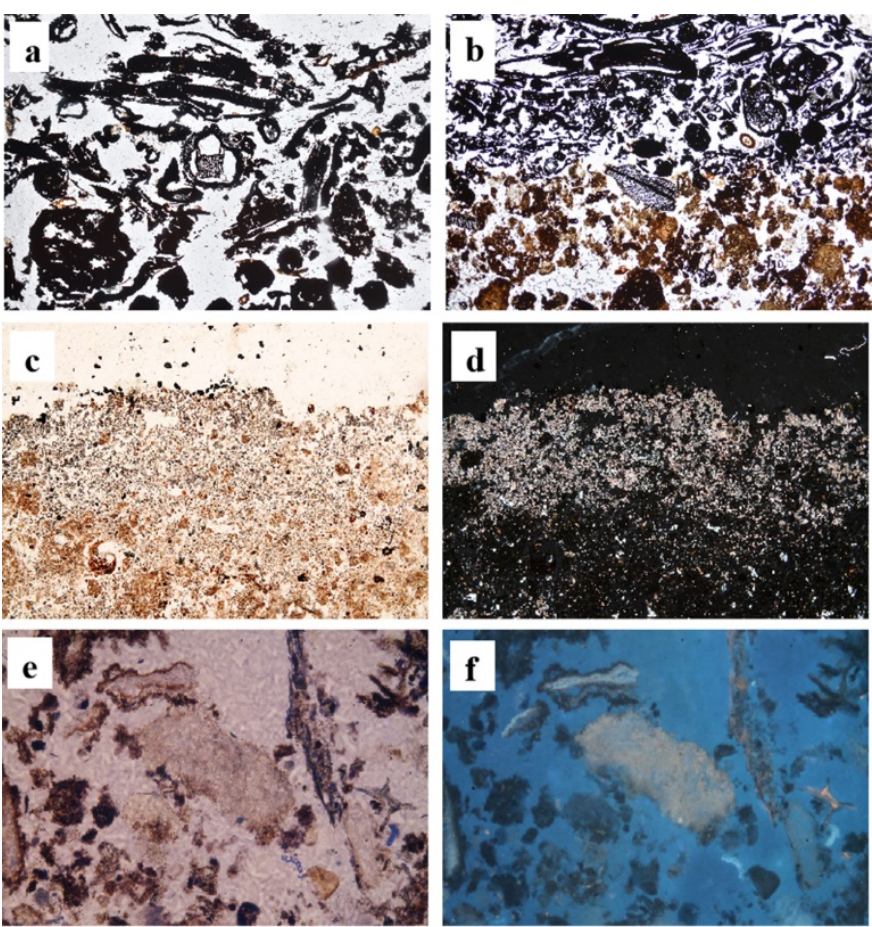

FIGURA 7. Residuos carbonizados (A), con agregados quemados (B). Cenizas pardo claro (C) de naturaleza calcítica (D) o fosfatadas depositadas en el espacio poroso (E) y con auto fluorescencia (F). Luz polarizada plana (A, B, C y E), luz polarizada cruzada (D) y luz fluorescente $(\mathrm{F})$. Longitud del marco $5.3 \mathrm{~mm}$.

La mineralogía de los Andosoles es útil para estimar la temperatura alcanzada en un incendio forestal sobre todo por los óxidos de Fe (ferrihidrita, hematita y maghemita) y los ferromagnesianos (augita e hiperstena). Estos resultados concuerdan con otros estudios experimentales o de caracterización de las propiedades térmicas de estos minerales, por lo que se puede indicar que la ferrihidrita es un buen indicador de temperaturas $<250{ }^{\circ} \mathrm{C}$ (Taylor, 1990), la hematita de $250{ }^{\circ} \mathrm{C}$ a 400 (Lide, 2001) y los ferromagnesianos $>400{ }^{\circ} \mathrm{C}$ (Huang, 1989) pero $<750{ }^{\circ} \mathrm{C}$. En algunos pinares se pueden alcanzar temperaturas hasta de $1150{ }^{\circ} \mathrm{C}$ (Mataix-Solera y Guerrero, 2007) en donde el cuarzo y los feldespatos se destruyen (Avgustinik, 1983), pero este tipo de minerales fueron dominantes aún en los arboles caídos ni en la base del Horno (H3 y H4).

\section{Temperatura del incendio y propiedades edáficas}

En el Grupo 1, en los incendios superficiales, la química y morfología de la hojarasca de los encinos y pinos, no marcó diferencia térmica. El arreglo laminar de la hojarasca de los encinos (Villers-Ruíz, 2006) y la rápida combustión de las acículas de los pinos (Wong y Villers-Ruíz, 2007) evitan que la temperatura supere los $250{ }^{\circ} \mathrm{C}$. Los cambios en el color de los suelos solamente alcanzaron los primeros cinco centímetros de profundidad, debido a que el suelo es un mal conductor térmico y la dirección de la flama y el calor es hacia arriba del suelo (Mataix-Solera y Guerrero, 2007). En el Grupo 2, los incendios incandescentes pero duraderos, e independientes a la especie arbórea, solo ocurren sobre material combustible de mayor tamaño, como troncos y árboles caídos y generan cambios más drásticos en las propiedades del suelo (Neary et al., 2005)

\section{Cenizas y propiedades del suelo}

En los sitios del Grupo 1, la incorporación de cenizas con diferente grado de incineración determinó los cambios en las propiedades edáficas. El aporte de material vegetal total o parcialmente calcinado favoreció el aumento de la MO, como lo han indicado Mataix-Solera y Guerrero (2007). El pH se incrementó, al igual que los cationes de potasio y sodio, resultados también encontrados por Certini (2005). Además, las cenizas blanquecinas cálcicas, se originan por la precipitación de carbonato de calcio, sobre todo en vegetación de Quercus sp. La CIC aumentó debido a la liberación de cargas procedentes de la destrucción de los complejos órgano-minerales, así como un aumento de cationes (principalmente de calcio y magnesio) cuando la temperatura supera los $300^{\circ} \mathrm{C}$ (Pereira, 2010). Finalmente, el contenido de fósforo soluble aumentó drásticamente debido a su liberación durante el proceso de incineración del material vegetal (Heydari et al., 2017) y trasformación de los minerales de rango corto que retienen fosfatos (Wada, 1989). Sin embargo, también se presentó cristalización de ortofosfatos en las cenizas blancas de los pinos, los cuales se identifican por su autofluorescencia (Karkanas y 
Goldberg, 2018). De acuerdo con Brady y Weil, (1999) los incendios constituyen una forma de reciclado de nutrientes.

Los cambios más drásticos se presentaron en el Grupo 2, donde la combustión de árboles y raíces duró más de 24 horas. La MO a esas temperaturas se desintegra completamente (Knoepp, Elliott, Vose y Linton, 2009), al igual que el humus y disminuye la superficie de intercambio generando un descenso de la CIC (González, Fernández y Gimeno, 1992). El aumento de sodio y potasio está relacionado con altas temperaturas; por ejemplo, Pereira (2010) indica que $>400{ }^{\circ} \mathrm{C}$ estos cationes se liberan de manera más prominente Finalmente, la pérdida de fósforo se atribuye a que el suelo se calentó por encima de su punto de volatilización durante un largo periodo de tiempo (Santín, Otero, Doerr y Chafer, 2017).

El cambio de color de algunas muestras se debe a la combinación del suelo con las cenizas de diferentes tonalidades, negras por carbonización $\left(150{ }^{\circ} \mathrm{C}-200{ }^{\circ} \mathrm{C}\right)$, grisáceas $\left(300{ }^{\circ} \mathrm{C}-500{ }^{\circ} \mathrm{C}\right)$ y blancas $\left(>500{ }^{\circ} \mathrm{C}\right)$ cuando la incineración es total (Pereira, 2010). Sin embargo, en los resultados encontrados, las cenizas grises y blanquecinas también se encontraron en los incendios superficiales y de copa que no superaron los $250{ }^{\circ} \mathrm{C}$ por lo que depende también del tipo de vegetación. De acuerdo con Ulery y Graham (1993) las coloraciones rojizas, como ocurre en las muestras del "Horno" o en la formación de pseudoarenas, se deben a las transformaciones de los óxidos de hierro.

La textura presentó dos procesos, en el Grupo 1 disminuyó el porcentaje de arena, que se atribuye a la fragmentación de los minerales en partículas más finas (limos) (Ulery y Graham, 1993) y en el Grupo 2 incrementó drásticamente el porcentaje de arena por la fusión de partículas tanto de limos y arcillas, formando pseudoarenas o pseudotexturas, que ocurre a temperaturas mayores a 500 ${ }^{\circ} \mathrm{C}$ (Minervini, Morrás y Taboada, 2018), con lo cual se altera la distribución de partículas y se modifica la clase textural (Ulery y Graham, 1993).

$\mathrm{El}$ aumento en los niveles de retención de humedad de capacidad de campo (CC) se debe a la cantidad de cenizas depositadas en la superficie del suelo, en las que se presenta una gran cantidad de espacio poroso (microporos $<50 \mu \mathrm{m}$ ), el cual es apto para ser ocupado por el agua como lo indica Balfour y Woods (2010).

En cuanto a su microestructura y porosidad, en el Grupo 1, los agregados de la parte superficial tuvieron contacto directo con el calor lo que causó micro explosiones y se disgregaron formando microagregados, provocadas por la expansión rápida del vapor del agua y aire en su interior. En el Grupo 2, los terrones con estructura masiva se formaron a temperaturas cercanas a los $500{ }^{\circ} \mathrm{C}$, donde la combustión duró más de 24 horas. Estas estructuras son favorecidas por la presencia de hierro que se fusiona con los aluminosilicatos característicos del material parental de estos suelos (Giovannini y Luchchesi, 1997).

\section{CONCLUSIONES}

El incendio forestal estudiado presentó dos tipos: superficiales y de copa en Quercus sp. y Pinus sp.

El análisis mineralógico de los Andosoles (destrucción, formación y dominancia de minerales) puede ser útil en la estimación de las temperaturas que alcanza un incendio forestal. Los óxidos de hierro, ferromagnesianos y formación de pseudoarenas de la fracción gruesa y fina se pueden utilizar para estimar y agrupar la temperatura alcanzada en los incendios forestales en Andosoles. Grupo $1<250{ }^{\circ} \mathrm{C}$ en incendios superficiales y de copa en la superficie (cinco centímetros de profundidad) independientemente de la vegetación; y entre $250{ }^{\circ} \mathrm{C}-500$ ${ }^{\circ} \mathrm{C} \_$en materiales que continuaron calcinándose como en troncos caídos y raíces (hasta $60 \mathrm{~cm}$ de profundidad).

Las propiedades químicas $\left(\mathrm{MO}\right.$, fósforo, $\mathrm{CIC}, \mathrm{pH}, \mathrm{K}^{+}$ y $\mathrm{Na}^{+}$) y físicas (color y textura) muestran tendencias de acuerdo con la temperatura alcanzada. En temperaturas < $250^{\circ} \mathrm{C}$, los cambios en las propiedades edáficas mejoran su calidad; en tanto que a temperaturas entre $250{ }^{\circ} \mathrm{C}$ y $500{ }^{\circ} \mathrm{C}$ su efecto es contrario, pero con menor área de impacto.

La acumulación de residuos carbonizados y cenizas están relacionados con la $\mathrm{MO}$, micro-agregados y porosidad que incrementan la retención de humedad y pueden ser cálcicas en Quercus sp. y fosfatadas en Pinus sp. con pastizal. 
Las mezclas de este tipo de cenizas pueden ser útil para la posterior reforestación de las zonas afectadas.

Los resultados muestran que los incendios vuelven a presentar una naturaleza dual, pero ahora relacionada con la temperatura alcanzada en el suelo, lo cual es necesario considerar en el combate de incendios o manejo de quemas prescritas con fines de manejo forestal.

\section{REFERENCIAS}

Adame, S., Oropeza, J., Martínez, M., Santoyo, V., \& Ramírez, M. (2000). Evaluación económica del Proyecto de rehabilitación de suelo en la cuenca del río Texcoco. Agrociencia, 34(4), 509-521.

Avgustinik, A. (1983). Cerámica. Lerez, España: Editorial Reverte, S. A.

Balfour, V. \& Woods, S. (2010). Physical and hydrological properties of vegetative ash. En Annual Meeting of the Montana Chapter of the American Water Resources Association. Montana, USA.

Bodi, M., Martin, D., Balfour, V., Santin, C., Doerr, S., Pereira, P., Cerda, A., \& Mataix-Solera, J. (2014). Wildland fire ash: production composition, and eco-hydro-geomorphic effects. Earth-Science Reviews, 130, 103-127. doi. 10.1016/j.earscirev.2013.12.007.

Borchardt, G. (1989). Smectites. En J. B. Dixon \& S. B. Weed (Eds.), Minerals in Soil Environments (2a ed.) (pp. 675-728). Wisconsin, USA: SSSA Book Series1.

Boul, S. W., Southard, R. J., Graham, R. C., \& McDaniel, P. A. (2011). Soil Genesis and Classification. John Wiley \& Sons. New York, USA.

Brady, N. \& Weil, R. (1999). The nature and properties of soils. London, UK: Prentice Hall. Inc.

Brownlow, A. H. (1996). Geochemistry (2a ed.). New Jersey, USA: Prentice Hall.

Certini, G. (2005). Effects of fire on properties of forest soils: a review, Oecología, 143(1), 1-10. doi: 10.1007/s00442-004-1788-8

Comisión Nacional Forestal [Conafor]. (2010). Incendios forestales: Guia práctica para comunidades ( $3^{\mathrm{a}}$ ed.). Jalisco, México.

García, E. (1998). Modificaciones al sistema de clasificación climática de Köpen (para adaptarlo a las condiciones de la República Mexicana) (5a ed). México, D.F.: Universidad Nacional Autónoma de México.

Drees, R. L., Wilding, L. P., Smeck, N. E., \& Senkari, A. L. (1989). Silica in soils: quartz and disorder silica polymorphs. En J. B. Dixon, \& S. B. Weed, (Eds.), Minerals in Soil Environments (2a ed.) (pp. 913974). Wisconsin, USA: SSSA Book Series1.

Giovannini, G., \& Lucchesi, S. (1997). Modifications induced in soil physic chemical parameters by experimental fires at different intensities. Soil Science. 162(7), 479-486. doi: 10.1097/00010694199707000-00003.

González, J., Fernández, C. \& Gimeno, P. (1992). Efectos de los incendios forestales sobre el suelo. Suelo y Planta, 2(1), 71-79.

Heinrich, E. (1972). Microscopy Petrography. McGraw-Hill Book Company, Inc.

Heydari, M., Rostamy, A., \& Dey, D. (2017). Effect of fire severity on physical and biochemical soil properties in Zagrus oak (Quercus brantii Lindl) forest in Iran. Journal of Forestry Research, 28(1), 95104. doi: 10.1007/s11676-016-0299-x.

Huang, P.M. (1989). Feldespars, Olivines, Pyroxenes and Amphyboles. En J. B. Dixon \& S.B. Weed (Eds.), Minerals in Soil Environments (2a ed.) (pp. 976-1050). Wisconsin, USA: SSSA Book Series 1.

International Centre for Diffration Data [ICDD] (2002). Mineral Name Search Results.

The International Union of Soil Science [IUSS], Grupo de trabajo de la World Reference Base [WRB] (2015). Base Referencial del Recurso Suelo. Sistema internacional de clasificación de suelos para la nomenclatura de suelos y la creación de leyendas de mapas de suelos. Informes sobre recursos mundiales de suelos 106. Roma: FAO.

Karkanas, P. \& Goldberg, P. (2018). Phosphatic features. En G. Stoops, V. Marcelino, \& F. Mees, (Eds.), Interpretation of micromorphological features of soils and regoliths (2a ed.) (pp. 323-346). Amsterdam, Netherlands: Elsevier.

Knoepp, J., Elliott, K., Barton, C., \& Vose J. (2009). Effects of prescribed fire inmixed oak forests of the southern Appalachians: forest floor, soil, and soil solution nitrogen responses. Journal of the Torrey Botanical Society, 136(3), 380-391. Recuperado de: http:// coweeta.uga.edu/publications/10367.pdf

Lide, D. R. (Ed.). (2001). CRC handbook of chemistry and physics (82 ${ }^{\text {nd }}$ ed.). New York, USA; CRC Press.

Mataix-Solera, J. \& Guerrero, C. (2007). Efectos de los incendios forestales en las propiedades edáficas. En Mataix-Solera, J. (ed.), Incendios Forestales, Suelos y Erosión Hídrica (pp. 5-40). Alicante, España: Caja Mediterráneo CEMACAM Font Roja-Alcoi.

Minervini, M., Morrás, H., \& Taboada, M. (2018). Efectos del fuego en la matriz del suelo. Consecuencias sobre las propiedades físicas y mineralógicas. Ecología Austral, 28(1), 12-27. doi.org/10.25260/EA.18.28.1.0.127

Murphy, C. (1986). Thin section preparation soils and sediments. Berkhamsted: AB Academic Publishers.

Nanzyo, M. (2002). Unique properties of volcanic ash soils. Global Environmental Research, 6, 99-112. 
Neary, D., Ryan, K. C., \& DeBano, L. (2005). Wildland fire in ecosystems: effects of fire on soils and water (General Technical Report. RMRSGTR-42) (Vol 4. pp. 29-52). USDA Forest Service.

Pereira, P. (2010). Effects of fire intensity in ash chemical and physical characteristics of Mediterranean species and their impact in water quality. Tesis de doctorado, Universidad de Barcelona. España.

Santín, C., Otero, X. L., Doerr, S. H, \& Chafer, C. J. (2017). Impact of a moderate/high severity prescribed eucalypt forest fire on soil phosphorous stocks and partitioning. Science of the Total Environment, 621, 1103-1114. doi: 10.1016 j.scitotenv.2017.10.116

Shoji, S. \& Takahashi, T. (2002). Environmental and agricultural significance of volcanic ash soils. Global Journal Environmental Research, 6, 133-135.

Shvidenko, A. \& Nilsson, S. (2000). Extent, distribution and ecological role of fire in russian forest. En E. S. Kasischke \& B. J. Socks (Eds.), Fire, climate change, and carbon cycling in the boreal forest (pp. 132-150). Ecological Studies: Analysis and Synthesis. New York, USA: Springer.

Simard, A. J. (1991). Fire severity, changing scales, and how things hang together. International Journal of Wildland Fire, 1, 23-34.

Stoops, G. (2003). Guidelines for analysis and description of soil and regolith thin sections. Soil Sciences Society of America, Inc. Madison, Wisconsin, USA.

Stoops, G. (2007). Micromorphology of soils derived from volcanic ash in Europe. A review and synthesis. European Journal Soil Science, 58, 356-377.

Taylor, R. M. (1990). Some observations on the formation and transformation of iron oxides. En Boodt, M., Hayes, M., \& Herbilton, A. (Eds.), Soil colloids and their associations in aggregates. New York, USA: Plenum Press.

Ulery, A. L. \& Graham, R. C. (1993). Forest fire effects on soil color and texture. Soil Science Society of American Journal, 57, 135-140.
Van Reeuwijk, L. (2002). Procedures for soil analysis. International Soil Reference and Information Centre-Food and Agriculture Organization of the United Nations.

Villers-Ruíz, M. L. (2006). Incendios forestales. Ciencias, 81, 60-66.

Wada, K. (1989). Allophane and Imogolite. En J. B. Dixon, \& Weed, S.B. (Eds.), Minerals in Soil Environments (2a ed.) (pp. 1051-1988). Wisconsin, USA: SSSA Book Series1.

Wong, J. \& Villers-Ruiz, M.L. (2007). Evaluación de combustibles y su disponibilidad en incendios forestales: un estudio en el Parque Nacional La Malinche. Investigaciones Geográficas MX, 62, 87-103.

Yamada, I. \& Shoji, S. (1983). Properties of volcanic glasses and relationships between the properties of tephra and volcanic zones. Japanese Journal of Soil Science and Plant Nutrition, 54, 311-318.

Manuscrito recibido el 14 de febrero de 2019

Aceptado el 1 de agosto de 2019

Publicado el 11 de abril de 2020

Este documento se debe citar como:

Hernández V., G. A., Gutiérrez C., M. C., Barragán M., S. M., Ángeles C., E. R., Gutiérrez Castorena, E. B., \& Ortiz S., C. A. (2020). La mineralogía en la estimación de las temperaturas de los incendios forestales y sus efectos inmediatos en Andosoles, Estado de México. Madera y Bosques, 26(1), e2611932. doi: 10.21829/myb.2020.2611932.

Madera y Bosques por Instituto de Ecología, A.C. se distribuye bajo una Licencia Creative Commons Atribución-NoComercialCompartirlgual 4.0 Internacional. 